\title{
The Team Film Genre
}

\author{
By Jeremy Strong
}

Fall 2006 Issue of KINEMA

\section{CREWS, SQUADS, SEVENS, ELEVENS AND DOZENS: THE TEAM FILM GENRE}

THIS article argues that there exists a genre that it terms the team film. It is not claimed that the films discussed have previously resisted generic analysis, for they also have characteristics that locate them in a wide range of other genres. Rather, it is contended that by virtue of key shared properties - including textual features, the audience expectations and interpretive strategies they provoke, and marketing practices - these films additionally may claim affiliation to, and invite understanding in terms of, a common genre.

Andrew Tudor maintains that:

Genre notions - except the special case of arbitrary definition

- are not critics' classifications made for special purposes;

they are sets of cultural conventions. Genre is what we

collectively believe it to be.

\section{(Tudor 139)}

It should be acknowledged that what follows runs the risk of appearing to be such an arbitrary definition, as "team film" is not a term circulating among a community of users in broad agreement as to its significance and neither is there any consensus that the body of texts or textual properties discussed may be understood collectively. Equally, if the interpretation applied here is arbitrary it is not the arbitrariness of grouping together, for example, films by left-handed directors. While there is an absence of popular or critical recognition for what this essay terms the team film it will be claimed that the set of attributes that ordinarily facilitate the recognition and consideration of particular genres are present.

One outcome of pursuing the present study has been to avoid the methodological circularity of what Tudor describes as the "empiricist dilemma." (138) Edward Buscombe summarizes this problem thus:

(I)f we want to know what a western is, we must look at certain kinds of film. But how do we know which films to look at until we know what a western is? (Buscombe in Grant 15)

The grouping together of certain films in this essay and the argument advanced in relation to them did not arise from an a priori understanding that the texts comprised a group. Rather, it derived from the viewing of a range of films, initially for other purposes, from which emerged an impression that some ostensibly different movies seemed to have something in common. As a tentative sense and enumeration of shared features developed, the viewing and re-viewing of films took on a correspondingly deliberate direction. What unfurled, beneath and alongside the markers and structures of other genres, appeared to constitute both a genre in its own right and the reasons for its un-regarded condition. Much of what follows concerns that which team films share but it is worthwhile briefly to address that which they do not; The Western invariably finds its way into such discussions because of its rich utility in exemplifying what a genre is; helpfully specific in terms of time and place, it offers up an unmatched iconography of easily recognizable elements and tends to deploy those elements in familiar ways. Conversely, the team film does not offer any such consistency of setting, costume or available technology but must borrow such elements from other genres and, in adopting their uniform, appear to join their ranks. Neither do team films adopt a consistency of approach in their structuring and handling of elements; some are clearly comedies, others clearly not, many feature comic scenes in otherwise broadly non-comic texts. Given this diversity, the texts discussed do not initially invite understanding in terms of homologies.

In his 1984 essay "A Semantic-Syntactic Approach to Film Genre" Rick Altman argued that genres achieve solidity when a recognizable semantics - the "what" of settings, motifs, character types and technical-stylistic elements - is consistently paired with a stable syntax - the "how" those semantic components are ordered in a structure. (Altman, Film/Genre 216-25). Although Altman has since indicated that the essay failed to recognize the "multi-discursive" nature of genres, that they are "mechanisms for co-ordinating diverse users" (208) it still provides a useful avenue of examination, albeit one that needs to be tempered by an 
awareness that team films exist in a complex web of other generic affiliations that beget and manifest their own semantics and syntax. This essay contends that team films are distinguished by their adherence to another, additional, semantic palette and syntactical structure, that alongside other signs and cues that mark them variously as westerns, war films, actioners, caper movies, sports films and comedies there may be discerned a common outline. Altman observes that "most genre distinctions depend heavily on textual concerns" (Altman 84), and the present argument certainly centres on this aspect of the films in question, though consideration is also given to understandings of genre concerned with matters outside the texts.

\section{Towards a definition}

A straightforward beginning is to state that a team film involves a group working towards a particular objective. However, goal-orientation is a widely-shared plot attribute of many texts and genres (Bordwell \& Thompson, 68-69) and it is also the case that the overwhelming majority of films involve a plurality of interacting characters. An element that distinguishes the team film then is that a heightened significance is afforded to the group as the means by which a given objective is attempted. This significance may be signalled by film titles which allude to the team itself, for example, The Magnificent Seven (Sturges, 1960) and The Dirty Dozen (Aldrich, 1967), or to the team objective; The Italian Job (Collinson, 1969), The Great Escape (Sturges, 1963), and more obliquely, Mission Impossible (De Palma, 1996). From film to film there is variation in the extent to which particular central characters may determine events and take up screen time but team films are recognizable by their insistence upon the relationship between group and goal. The team may be imperfect or compromised - indeed drama is commonly wrung from relationships and events that threaten to shatter the group - but it is unimaginable that the objective will be secured without a team effort. Hence, films that afford more than a certain share of interest and agency to a single character or duo cannot be said to be team films even though their milieux may be understood extra-textually as arenas of collective or collaborative endeavour. In this respect the team film is distinctly different to the many texts that emphasise the determining power of the individual who eschews, ignores or otherwise operates outside bureaucratic structures, though teams may themselves be unruly and placed in oppositional relationships to authority and meta-groups.

\section{The Gathering}

There is an early phase in each team film where a group is formed, re-formed or gathered. This develops through scenes devoted to individual team members that convey to the audience key insights into characters' talents and temperaments. These displays or discussions of skills - often matched with shortcomings - and insights into personal histories are generally initiated or witnessed by the character who assumes leadership for the team. The Usual Suspects (Singer, 1995), abetted by its flashback structure, subverts this convention of the team film by concealing until its end the identity of the character who causes the team to be formed and thereby sets the film's events in motion. Gatherings may take the form of a search for individuals already known to the searcher(s) or of a series of interviews that often involve the scrutiny of files and records and, hence, the economical conveyance of relevant information. The Wild Geese (McLaglen, 1978) employs both devices; the former for principal team members and the latter for more subsidiary roles. The Italian Job devotes much time to establishing the credentials of Michael Caine's "Charlie Croker" as a quick-witted criminal and comparatively little to the phase of team assembly; only one other member, "The Professor," merits a separate introductory scene. Other participants are introduced to each other, and the audience, around a large corporate-style boardroom table. The remake (Gray, 2003) strikes a different balance; at the

film's outset the team is already in place but an initially successful gold heist is followed by a betrayal that results in the death of a team member. To recoup their losses and exact revenge the remaining members plan to steal the gold back from their betrayer but need to recruit a replacement safe-cracker to do so. The introductory meeting of the re-formed team motivates a series of comic flashbacks that explain to the newcomer how other members acquired their nicknames. Mission Impossible also employs the device of a first task that elucidates the roles and skills of team members but which is sabotaged by betrayal, necessitating a re-constitution of the team.

\section{The Proposition}

Although the gathering is one of the clearest markers of the team film it is generally consequent upon another characteristic phase in which the principal goal or objective is stated. The reverse is most often true of movies where a lone hero or duo uncover or are presented with the task that will occupy them for the duration. For 
example, the credentials and lineaments of James Bond find expression in the opening minutes, signalling a modus vivendi that will inform his approach to a yet-to-be-presented task. With the team film it is usually the task that establishes the necessary characteristics of the yet-to-be-formed group. In the first scene of The Magnificent Seven the visit of bandits to a Mexican village establishes the need of the village to be defended, motivating the decision of three villagers to journey to a border town to buy guns. The actions of Yul Brynner's and Steve McQueen's characters in the following scene are not causally connected though they have a relevance that is noted by the on-looking villagers and audience alike. Their impromptu decision to drive the hearse bearing a dead Indian to Boot Hill in the face of armed opposition establishes their courage and perhaps ennui, their proficiency with firearms, and a tolerant-cum-charitable attitude to another ethnic group that telegraphs their eventual relationship with the Mexican village. A subsequent meeting between Brynner's "Chris" and the villagers results in a decision to hire out-of-work gunmen rather than buy guns and the phase of team formation begins. The Great Escape establishes the shared objective of the Allied prisoners-of-war in a flurry of ad hoc escape attempts when they arrive at the camp at the beginning of the film but it is only with the arrival of "Big X," Richard Attenborough, that roles are formally assigned to particular prisoners as part of a mass break-out scheme and a rigorous team effort commences. Although The Italian Job (2003) and Mission Impossible both begin with ready formed teams these are not the eventual groupings that will attempt the main task, the preparation for and execution of which will occupy most of each film's duration; in these films the statement of a fresh proposition motivates a new gathering.

\section{The Team}

Strong differentiation between individual team members is a key motif of the team film. Race, sex, size, class, mannerisms and sexual preference are among the most frequently deployed markers that facilitate ease of recognition for multiple characters and provide motivations for character interactions. In The Dirty Dozen Telly Savalas' "Maggot" is a Southern religious fanatic who expresses his contempt for Jim Brown's angry "Jefferson" in an early scene. This antipathy finds its resolution at a critical stage during the dozen's secret mission when Maggot's madness jeopardizes the operation and Jefferson must kill him. The Magnificent Seven achieves a visual differentiation between team members largely in terms of attire. Their clothing also has connotative value that reinforces interpretations of the characters as types; Brynner's Chris, in striking all black, is the leader, Bronson conveys blue-collar grittiness (as he does in The Great Escape and The Dirty Dozen), McQueen's stove-pipe chaps suggest a footloose cowboy sensibility, Vaughn is marked as dandyish and a potential liability, Coburn in muted beige is the quiet efficient killer, Buchholtz's off-the-peg gunfighter clothes signal his wannabe, newcomer status. In the war film the ubiquity of military uniform limits the extent to which clothing may serve as a differentiator or cipher. Accordingly, The Dirty Dozen emphasises ethnicity, underpinned with appropriate character names and accents, and size; early in the film the dozen are ordered to form a row according to height and later an officer observes that they range from a "dwarf" to a "giant." Koszarski notes that the motif of "the variegated platoon" (Koszarski 186) dates as far back as The Big Parade (Vidor, 1925) but this is not to claim that all films involving such differentiation are team films. Clear character differences, both in terms of visual and other codes and conflicting worldviews that drive plot development, are manifest across a range of texts and especially in US war pictures concerning World War Two where the need to reconcile oppositions within the small military unit resonates as a synecdoche for the heterogeneous nation. Rather, the war film may be identified as an antecedent strand in the eventual development of the team film and "variegation" as a necessary but not sufficient condition for identifying the genre.

\section{The Line-Up}

Certain images of the group together at significant junctures in the film, for example at the first moment of team assembly, or prior to embarking upon a mission, constitute a recurrent feature in the vocabulary of the team film. Static compositions (facilitated by the widescreen ratios that became the norm by the 1960s), dolly shots and pans involving the horizontal arrangement of the team in a formal line-up or parade are frequently deployed and signposted as important; The Dirty Dozen, after several minutes' exposition, only begins its credit sequence proper and theme tune when the dozen have been formed into a rank. The Untouchables (De Palma, 1987) makes a deliberate allusion to The Magnificent Seven in a line-up of its team on horseback, drawing on the iconography of the earlier film and the Western generally. Artwork and publicity materials associated with the films often use these images, cueing the viewer to expect inter alia movies that will articulate properties in common with other texts that do likewise. The Usual Suspects used 
the tagline "Five Criminals. One Line Up. No Coincidence" and made the line-up the defining image of its release campaign. The film locates this scene between the sequences of the team-in-waiting being arrested individually and the interviews that lead into the jail-cell discussion of a possible team job. Only the most attentive viewer is likely to notice or impute significance to the absence of the narrating "Verbal," Kevin Spacey, from the arrests and questioning sequences It is the very pleasure of watching a particular convention enacted - the introduction to the talents and idiosyncrasies of a particular team - that distracts us from this crucial elision.

Movies involving soldiers or prisoners find straightforward narrative justifications for the physical arrangement of the team into this signature collocation. Indeed, the recurrence of the soldier-as-prisoner theme is notable; The Dirty Dozen, The Great Escape, Escape to Victory (Huston, 1981) the latter also having a sports theme, itself the occasion of formal line-ups of participants. Where a military, prison or sports dimension is not present it is nonetheless common that the team is organised along quasi-military lines; introductions and briefings actuating to some degree the observance of this element of the team film rubric.

\section{Misfits}

Within the team film genre there may be recognized a misfit tradition, appearing both as a distinct subset and a more widely dispersed tendency inflecting a great many texts. Misfit teams are invariably constituted according to principles of unlikeliness and unsuitability; the wrong backgrounds, past failures, diverse foibles, and a state or history of antipathy between key figures are the sources of narrative grist and sometimes comedy. Once the unlikeliness of the team has been firmly established, often by reaching a nadir of underachievement, a turnaround in talents and fortunes follows. The overcoming of individuals' weaknesses nourishes an improved group dynamic by which the misfits are transformed. Cool Runnings (Turteltaub, 1993), A League of Their Own (Marshall, 1992), Space Cowboys (Eastwood, 2000) and Major League (Ward, 1989) exemplify this mode, positing respectively race, sex, age and a catholicity of shortcomings as the original obstacles to success. However, the misfit tradition is usually figured in more nuanced terms. The premise of The Dirty Dozen, that twelve condemned military prisoners will be trained for a dangerous covert operation, suggests initially a mismatch between team and goal but as their training proceeds it becomes apparent that the men have particularly relevant talents, all of which have a direct bearing on the cause of their imprisonment; cunning, physical strength, independent thinking. When tested against conventional soldiers in a military exercise the dozen triumph. The Devil's Brigade (McLaglen, 1968) figures the unlikeliness of its team in terms of a structuring opposition; half the brigade is composed of crack troops, the other half are rejects, grifters and trouble-makers. As with The Dirty Dozen it is the attainment of synergy and the revelation that character flaws and problematic histories are in fact concealed talents and virtues that enables the now-united team to pass a first test and proceed to a larger objective. Armageddon (Bay, 1998) advances on the fundamentally implausible proposition that it is more practicable to teach oil-drillers to become astronauts than vice-versa. As such, its team are both the best-of-the-best and misfits; their credentials as skilled oilmen are established in the opening minutes but scenes of their subsequent training at NASA make numerous comic allusions to The Right Stuff (Kaufman, 1983) in terms of their unsuitability for the mission. Yet, despite the outright voicing of the view that the team represent "The Wrong Stuff," by the time of embarkation their walk to the shuttle is photographed, scored and played in an unmitigated heroic and stirring idiom.

\section{Preparation}

Scenes of the team involved in preparatory activities appear in most movies. These may take the form of a concentration on the acquisition and development of individual skills and readiness or, in instances where team members are already sufficiently skilled, of application to particular tasks. The Right Stuff devotes much attention to the physical testing of exceptional men in their prime while The Wild Geese and The Sea Wolves (McLaglen, 1980) concern retired soldiers summoned to a last mission. Both versions of The Italian $J o b$ involve stunt-driving practice that replicates the demands of the planned heist - played primarily for comedy in the earlier film - and Ocean's Eleven (Soderbergh, 2002) features the construction of a replica casino vault which functions not only as a training vehicle but, in a twist previously concealed from the audience, also plays a critical role in the eventual coup. Recent team films have tended to misdirect viewers by effecting key elisions amid the welter of diagrams, models, exchanges and activities that elaborate the plan. In The Italian Job (2003) original preparations are rendered largely redundant when the team's target 
becomes aware of their intentions and a new plan, of which viewers are only privy to a part, is put into action. It is then unclear whether events are proceeding successfully and the significance of aspects of the team's preparations only becomes obvious as the heist unfolds. Similarly, what appears to be a major snag in Ocean's Eleven (2002) when an elderly team member, whose suitability has earlier been questioned, appears to have a heart attack, is subsequently revealed to be a part of the plan. Such innovations develop from the established tendency for difficulties to be introduced in preparatory and training scenes, heralding likely crisis points in the execution of the mission (such as the propensity of tunnels to collapse in The Great Escape) and for certain characters to be flagged as weak-links. Montage devices are regularly in evidence during the preparation phases of team films; a succession of abbreviated scenes, usually involving repeated actions and conveying a sense of progress and the passage of time. Often overlaid with the film's theme music, montage scenes may simultaneously address several characters engaged in activities that are physically separate but which cohere in the overall plan, though, if required, the interrupted nature of montage also facilitates the obfuscation of important absences.

\section{First-run-Main-event}

Team films manifest considerable variety in respect of this distinction but share a recognizable separation between a preliminary piece of team-work and a subsequent, paramount, task. In The Magnificent Seven the team have a successful first encounter with the bandits, initially believing that they have fulfilled their commission, but it is only after another more costly engagement that victory is achieved. The crew in The Usual Suspects execute an initial heist that causes the downfall of a crooked cabal within NYPD but their final operation in San Pedro harbour results in the death of all team members except Verbal who is revealed to be the master-criminal "Keyser Soze." Mission Impossible is structured around three set-piece tasks; the failed Prague mission which results in the death of several members, necessitating a re-constitution of the team; the Langley mission, where information is taken from a well-protected vault; and the channel tunnel mission in which Tom Cruise's "Ethan" unmasks his betrayer and clears his name. In the second of these exercises Mission Impossible demonstrates the propensity for more recent team films to intermingle the planning and execution phases rather than effect a clear temporal separation. Monologue from a briefing scene becomes the voice-over to the operation itself as the image-track switches to the subsequent event. Such asynchronous representations are instrumental in the overall practice of misdirecting and unsettling audiences accustomed to the clearer order of earlier team films, though their repeated deployment ratifies their own place in the genre's system.

\section{The Coda}

A re-gathering of the team at the film's close is a frequently repeated motif, often effecting a mood of quietude after the pell-mell of the main event though sometimes having an up-beat and abrupt flavour. Milestone's Ocean's Eleven (1960) and the Soderbergh re-make have their teams assembled somewhat aimlessly before drifting apart; in the former they are positioned below a Las Vegas billboard that bears the actors' names, cementing the interpretation that they have done little besides playing themselves; in the latter a similarly reflective, even melancholy, tone is sought as the team stand silently before a casino fountain, though this is in the context of a successful heist and is followed by a flash-forward to "Danny," George Clooney, being released from prison. In The Great Escape and The Dirty Dozen, where teams have been significantly reduced by death, the re-gathering is effected by a recapitulation in the end credit sequence using images of the individual team members, each lasting a few seconds. ${ }^{(1)}$ Armageddon deploys an especially saccharine variant of the motif, merging the melancholy and the upbeat, in a final marriage scene where all surviving team members are physically present while the heroic departed, including the father of the bride, are represented by photographs on easels.

An unusual case to consider in terms of the coda and the team film is Predator (McTiernan, 1987) a movie at the very margins of the genre but evidently shaped by its norms. Predator is an Arnold Schwarzenegger vehicle, one of several action films constructed to showcase his physical presence and sidestep his limitations. The narrative structure and commercial logic of such lone star vehicles are essentially antipathetic to those of the team film; where the former follows a principle of centrality, commonly in terms of the rehearsal of familiar characteristics and values, the latter tends toward a promise of interaction and diffused interest; a schema no less codified and predictable in its own way, but one that militates against the fixity of certain stars and their significance. Predator represents a partial anomaly to the pattern of previous and subsequent 
Schwarzenegger films in that his "Dutch" is part of an elite seven-man unit rather than a sole agent, or, as is the case in a number of his movies, the physically-imposing element of a duo. He is, of course, the most important part of the group, the leader, the strongest, and eventually the last man standing but it is notable that the group is a copybook example of individual differentiation in the team film. Ethnicity, quirks, physical size, variations on military uniform and different weaponry distinguish a team that includes a tobacco-chewing redneck, a genuflecting Latino, a taciturn Native American and a shaving-fixated black man.

While Predator does not address team selection or training, the helicopter journey into the jungle establishes the distinguishing characteristics and names of team members, generating a sense of the individuals that is borne out by their subsequent actions and exchanges. However, the film then adheres to the pattern of many contemporary horror films by having its eponymous monster successively eliminate all team members except Dutch by the half-way point, leaving him to tackle it on his own for the remainder. It appears that the conventions of the team film actioner have been jettisoned in favour of those of an Alien (Scott, 1979) or Halloween (Carpenter, 1978); the team and team-work have not proved critical to what becomes the film's principal goal - the defeat of the monster - a feat accomplished by an improvising lone survivor. Yet the team enjoy an unexpected and rather jarring reprise in the form of a prototypal team film coda in which long-since-forgotten individual team members smile at the camera, terminating in a freeze-frame of a more aloof Schwarzenegger.

\section{A (Brief) History}

Claims concerning the beginnings of particular genres, especially "first" films, are notoriously difficult, commonly imposing, as Musser (1984) and Altman (1999, 34-38) demonstrate, a retrospective categorisation upon texts that would not have been recognized by their makers or original audiences. As the present study addresses what it regards as an essentially un-recognized genre this might appear a singularly inadequate justification for the failure to petition for a particular text as inaugural. However, the matter of the extent to which the team-film might be recognized as distinct will shortly be returned to, and the notion of a founding text substituted by an interpretation that involves more than one movie and the coalescence of several filmmaking tendencies.

The Seven Samurai (Kurosawa, 1954) and the transposition of that story to a western setting in The Magnificent Seven constitute the important early phase of the team film genre. The following excerpt from a contemporary Variety review ${ }^{(2)}$ of the Seven Samurai indicates the extent to which it manifests key characteristics outlined in this essay;

Bandits are waiting to attack an isolated village as soon as the rice is ripe. Some of the men go to look for help and run into a sage old Samurai warrior who consents to help them. Then follows a series of deft bits as the seven men are gathered and head for the village to prepare defenses, train the men, and get ready for the onslaught. They finally vanquish the bandits but not without losses. (Elley 846)

"Proposition," "Gathering," "Preparation" and "Main-Event" are clearly discernible, while "pic has a good feeling for characterization" and "(e)ach character is firmly molded" (846) suggest a recognition of the stress on differentiation between team members. The early presence of a misfit aspect is also signalled in the description of Toshiro Mifune's "Kikuchiyo" as "the bold, harebrained (sic) but courageous warrior" (846) The Magnificent Seven adheres closely to the structure and motifs of the earlier film, with many scenes and characters translating largely unaltered, but differs in that the subsequent film allies the derived material to a western setting that would prove familiar to US and international audiences and used actors who would also enjoy high audience recognition to fill most of the team roles. It is the latter aspect that appears critical to the development of the team film.

With cinema audiences declining from the mid 1950s the Hollywood majors strove to make larger and more impressive pictures that would encourage audiences to return. Stuart Klawans describes as "gigantism" the tendency that became dominant during this period: "As everybody noted at the time, movies were swelling up." (Klawans 120) This expansion was manifest in a variety of ways; in the new wide-screen processes, in escalating budgets, in longer running times, in a concentration on grand and spectacular topics - especially historical and biblical narratives - and in the practice of loading pictures with multiple stars to inspire interest 
from as large a potential audience as possible. With the team film a rubric developed that would maximize this last component, an intersection of casting and scripting quite different to more familiar practices of using well-known names to play villains, second fiddles and cameos; the team film allowed several actors a share of the available limelight both through narratives that stressed interaction towards a common goal and through selection and preparatory scenes in which each is, for a spell, the main attraction. A necessary caveat, however, is to that a Twenty-First century sense of the star status and saleability of actors in the original 1960s florescence of the team film is often different to their standing at the time of production, not least because of the success of the films in question.

In The Magnificent Seven only Yul Brynner was at the peak of his career, having recently won the Oscar for best actor in The King and I (Lang, 1956). Similarly, of The Dirty Dozen only Lee Marvin enjoyed such standing following The Killers (Siegel, 1964) and Cat Ballou (Silverstein, 1965). Steve McQueen's career prior to The Magnificent Seven had involved TV work ${ }^{(3)}$ on Wanted: Dead or Alive (1958 -1961) and a move from smaller to more noteworthy film roles including his first film with John Sturges, Never So Few (1959) that led directly to his key part in The Magnificent Seven. By the time of The Great Escape his marketability had increased to the extent that he took first billing, though greater celebrity still lay ahead of him in the wake of The Thomas Crown Affair (Jewison, 1968) and Bullitt (Yates, 1968). James Coburn and Charles Bronson would also follow Sturges from The Magnificent Seven to The Great Escape, both enjoying their periods of peak fame somewhat later; Coburn with the Flint movies (Mann, 1965) \& (Douglas, 1967), Bronson in a series of Michael Winner pictures in the early 1970s. The Dirty Dozen's roster merged actors on their way up with a number whose box-office draw was waning but who were nonetheless identifiable presences, the individual stars of earlier movies. John Cassavetes and Donald Sutherland brought an edgy, youth-oriented element to the film, their contributions anticipating movies of the 1970s, while Ernest Borgnine, Clint Walker and Robert Ryan had had their best of times a decade earlier.

If these casts were not composed entirely of stars at their zenith, they were nonetheless distinguishable for a promise of strength in depth, their marketing emphasising the extent to which the films offered a varied muster roll of notable presences and stories that would focus on their differentiation and interaction. Contemporary trailers for The Great Escape and The Dirty Dozen first establish the "Proposition" - respectively, a spectacular POW breakout and the training of twelve military prisoners for a sabotage mission - then devote most of their duration to presenting the cast individually in terms of their roles. The Great Escape trailer uses titles in conjunction with images of characters to signal both the actor-presence and the function their character will fulfil in the team and film; "Steve McQueen as 'The Cooler King," "James Garner as 'The Scrounger,"' "Charles Bronson as 'The Tunnel King." The Dirty Dozen trailer attributes voiced-over reflections on the personalities and motivations of successive characters to the relevant actors - "says Marvin...," "says Borgnine...," "says Brown..." - while individuals missed in this scheme are then included in an alphabetical cast list that scrolls up the screen.

This focus on the cast might suggest a homological relationship between the team film and those pictures that are sometimes described as ensemble films. However, this would be to ignore the significance of the other, textual, features enumerated in the present study. To illustrate this let us consider The Ladykillers (McKendrick, 1955) and the 2003 re-make (Coen). The original features a fine ensemble cast and a story-line that appears to beg for a team film approach, yet it is not a team film for the simple reason that all the constituent structures and motifs were not then established in the minds of its makers or viewers. Its comic villains are, of course, strongly differentiated in terms of size, ethnicity, appearance and background, there is a distinct misfit flavour, and they share an objective, but they are not gathered; they merely arrive as a ready-formed unit. Re-made nearly half a century later, and more than forty years into the span of an identifiable team film genre, the "Gathering" motif is irresistibly appropriate; individual comic scenes, each lasting a few minutes, establish the characteristics and shortcomings of the multifarious team-in-waiting before a planning meeting elucidates the team roles they will fulfil.

If the 1960s amounted to a Golden Age of the team film, the 1970s saw it largely displaced by a nearneighbour, the disaster movie. The similarities between the two genres are considerable; both involve groups of people who must work together toward a common objective, both address differences and tensions within the group, and both tended to feature casts that mixed actors at, past and near their peak, and on occasion actors best known outside the USA whose presence was intended to boost returns in particular overseas 
territories. Such movies as Airport (Seaton, 1970) and its three sequels, The Poseidon Adventure (Neame, 1972) and The Towering Inferno (Guillermin, 1974) are however marked by their adherence to the "Ship Of Fools" narrative scheme in which the group are thrown together by circumstances or predicament and their individual flaws exposed, rather than assembled for a purpose.

An additional tendency towards parallel action may be discerned in the disaster movie in which there is not only the trapped or isolated group but also an exterior party endeavouring to effect their rescue. The Flight of the Phoenix (Aldrich, 1965) reveals characteristics of both genres; a sandstorm causes a plane to crash in the desert, establishing the predicament that they are miles from safety and without transport, but it is the various talents of the people on board that facilitate the construction of a makeshift plane from the wreckage.

A later Aldrich picture, The Longest Yard ${ }^{(4)}(1974)$, in which a newly-arrived inmate is forced to form a prisoners' team to take on the guards, reveals a more straightforward team film narrative persisting into the era of the disaster movie, though the star presence of Burt Reynolds far exceeds the status of the film's other actors. In common with a number of the earlier team films, both have recently been re-made ${ }^{(5)}$. This suggests a certain vitality on the part of the genre, that it finds expression both in expensive all-star movies such as Ocean's Twelve (Soderbergh, 2004) and more parochial films like The Mean Machine (Skolnick, 2001). A certain dearth of movie-making imagination, by no means restricted to the team film, is simultaneously evident. Perhaps, however, in its application of new actors and story twists to well-understood situations

this re-making cycle bespeaks the very nature of genre's balance between familiarity and invention and of the particular pleasures of the team film.

\section{Notes}

1. Uncertainty prevails in the ordering of actors with respect to star status in such sequences; The Great Escape builds from the minor roles to Steve McQueen's "The Cooler King" while The Wild Geese begins with Richard Burton's "Col. Faulkner" and works downward, eventually showing some of the minor characters in pairs.

2. The version reviewed was the 161 minute international version, first screened at the 1954 Venice Film Festival. 3. A relationship with television may be observed with several actors of 1960s team films; for McQueen, Coburn and Marvin as a route to film stardom, for Bronson and Borgnine as part of a subsequent career, for James Garner as his true m?tier. 4. Released in the UK as The Mean Machine. 5. Flight of the Phoenix (Moore, 2004) \& The Mean Machine (Skolnick, 2001).

\section{References}

Altman, R. "A Semantic/Syntactic Approach to Film Genre," Cinema Journal 23, 1984, no. 3, 6-18.

Altman, R. Film/Genre. London: BFI Publishing, 1999.

Bordwell, D \& K. Thompson. Film Art: An Introduction. Sixth Edition. New York: McGraw-Hill, 2001.

Grant, B. K. Film Genre Reader. Austin: University of Texas Press, 1993.

Elley, Derek, ed. Variety Movie Guide '97. Hamlyn, 1996.

Klawans, S. Film Follies: The Cinema out of Order. Cassell, 1999.

Koszarski, R. An Evening's Entertainment: The Age of the Silent Feature Picture, 1915-1928. New York: Scribner's, 1990.

Musser, C. "The Travel Genre in 1903 - 1904: Moving Towards Fictional Narrative," originally published in Iris 2. Reprinted in Thomas Elsaesser (Ed.) with Adam Barker; 1990. Early Cinema: Space, Frame, Narrative. London: BFI Publishing, 1984, pp. 123 -132.

Tudor, A. Theories of Film. London: Secker and Warburg, 1974. 


\section{Author Information}

Jeremy STRONG is Head of Media at Thames Valley University, London. He has published in Literature / Film Quarterly, Gastronomica, and Paragraph. He is editor, with Garin Dowd and Lesley Stevenson, of Genre Matters: Essays In Theory and Criticism (Intellect Books, 2006). 